\title{
Alternatives for small, medium and micro scale enterprises participation in the renewable energy industry - small scale embedded generation review
}

\author{
E. Mkhwebane ${ }^{1 *}$, N. Ntuli ${ }^{2}$ \\ Energy Centre, Council for Scientific and Industrial Research, Pretoria, South Africa \\ 1. $h$ ttp://orcid.org/0000-0002-7884-0654 \\ 2. https://orcid.org/0000-0002-8200-5002
}

\begin{abstract}
Over the past decade South Africa has seen an increase in the uptake of solar energy as a result of the Renewable Energy Independent Power Producer Programme, which led to a sharp increase in procurement of utility-scale solar PV projects. On the other hand, the load shedding which was implemented by the national power utility in response to electricity supply and demand challenges resulted in the rise in procurement of small-scale embedded generation solar PV systems. While the REIPPPP has had minimal impact in terms of incorporating small, medium and micro scale enterprises (SMMEs) in the renewable energy value chain, there is a significant opportunity for SMMEs in the small scale embedded generation (SSEG) market segment. This study investigated the challenges and opportunities for SMMEs in SSEG.
\end{abstract}

Keywords: municipalities, REIPPPP

Journal of Energy in Southern Africa 30(2): 144-151

DOI: http://dx.doi.org/10.17159/2413-3051/2019/v30i2a6375

This work is licensed under a Creative Commons Attribution-ShareAlike 4.0 International License

Published by the Energy Research Centre, University of Cape Town ISSN: 2413-3051

https://journals.assaf.org.za/jesa

Sponsored by the Department of Science and Technology

\footnotetext{
* Corresponding author: Tel:+27 (0)12 842 7228;

email: SMkhwebane@csir.co.za
} 


\section{Introduction}

South Africa depends on fossil fuel for power generation, but is in a process of transitioning to cleaner energy source. However, changes in regard to the regulation and ownership of electricity generation pose challenges which are rooted in the socio-economic of the country and the heavy dependence on power generation from coal, as an argument to the energy transition (Baker, 2018).

Small-scale embedded generation (SSEG) refers to power generation facilities located at residential, commercial or industrial sites, where electricity is generally also consumed. These are mainly solar photovoltaic (PV) systems but also include other technologies, such as wind and biogas (SALGA, 2017). SSEG refers to the power that is generated, for the commercial, industrial or residential site that is under $1 \mathrm{MW}$ where the electricity produced is also consumed, this according to the Stellenbosch Municipality. SSEG presents opportunities for small, medium and micro scale enterprises (SMMEs) to participate in the renewable energy business. The objective of this study was to investigate such opportunities in the embedded generation market segment of solar PV in South Africa. Participation of SMMEs will contribute to economic growth and job creation.

\section{Background}

The motivation for residential and commercial/ industrial switching to embedded generation is the cost of electricity and reliability of supply. The energy transition had led to the need for decentralising the power system. This means that electricity consumers start to go off-grid as electricity prices rise. Load shedding had a big impact on consumers considering alternative options to meet their energy supply needs. In this way a traditional electricity consumer becomes a 'prosumer', meaning they become active contributors to the electricity supply
(Zhang, Wu et al., 2018). Most businesses see value in installing rooftop solar PV systems as part of their sustainability programmes. SSEG offers an opportunity to low-carbon, decentralised and cheaper energy.

There are several options for implementing embedded generation projects (see Figure 1). The first is self-consumption and feeding access electricity to the grid. This option requires a net metering arrangement with the municipality. The second is generation of electricity with the purpose of supplying a specific customer, which requires a wheeling arrangement via grid connection and supply for a specific customer. The last option is self-consumption without grid connection, which usually occurs in places where there is no grid access and the systems are coupled with a small battery storage system.

A report by Üçtuğ and Azapagic (2018) recognises the role of solar PV technology in decarbonising the power sector. The technology has seen massive growth in many countries, with supply exceeding $1 \%$ of demand in 2015, largely driven by incentives such as feed-in-tariffs, the ability to generate electricity which is fed back to the grid, and by payments to prosumers for the power generation. What makes solar PV a technology of choice is its ability to use a free natural resource (sunlight), the fact that it requires minimum maintenance, it is modular and can be deployed rapidly and reliably.

\subsection{Implementation of SSEG in South Africa}

Solar PV technology was introduced to South Africa in the 1980s with a few small-scale installations, predominantly in rural, off-grid areas. In the 1990s, a few installations of commercial scale started being implemented, although the scale was still not over a megawatt, but only in the tens of kilowatts (Breyer and Gerlach 2013a).

The embedded generation market in South



Figure 1: Small-scale embedded generation options. 


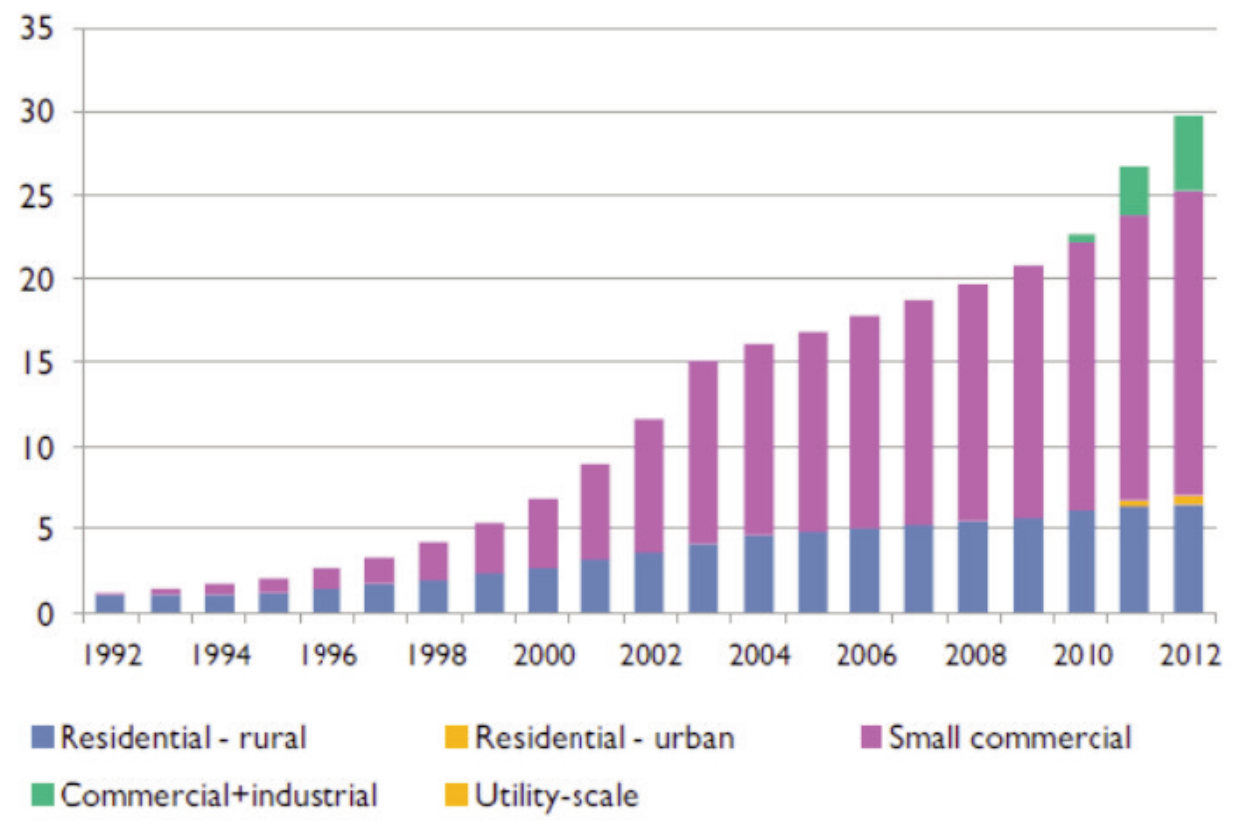

Figure 2: Solar PV installed capacity.

Source: Breyer and Gerlach (2013a)

Africa has a long history. Rycroft (2017)(Rycroft, 2017) estimates the number of small-scale PV systems installed in South Africa at July 2017 at 138 400, with a capacity of 144 MW, covering residential and commercial/industrial (airports, distribution centres, factories, filling stations, business parks, hospitals, shopping centres, mines and offices) usage, the latter is increasing faster than residential usage. The draft NERSA guidelines on embedded generation prescribe a maximum of $1 \mathrm{MW}$ that can be approved by municipalities for grid connection without requiring a generation licence. Projects that exceed $1 \mathrm{MW}$ are required to show proof of registration with the National Energy Regulator of South Africa (NERSA) or an exemption letter (SALGA and Genesis 2017).

The recent draft Integrated Resource Plan (IRP 2018) makes provision for the installation of 2600 MW of small-scale embedded generation by 2030 . This is the first time in the energy planning history in South Africa that government acknowledges selfconsumption as an important part of the energy mix. It opens business opportunities for organisations that would like to break into the renewable energy project development space.

\subsection{Role of SMMEs in the renewable energy sector}

The definition of the SMME, according to the Department of Trade and Industry, is classified according to the number of employees, as well as the organisation's annual turnover (see Table 1). However, different targets are set per sector, with the maximum number of employees being 200 for a medium enterprise and the maximum annual turnover being R64 million (for wholesale trade, commercial agents and allied services) (The
Banking Association South Africa 2018). Table 1 Classification of SMME shows the different categories and number of employees as well as the annual turnover.

Table 1: Classification of SMMEs

\begin{tabular}{lcc}
\hline Class size & $\begin{array}{c}\text { Total fulltime paid } \\
\text { employees (max) }\end{array}$ & $\begin{array}{c}\text { Total annual } \\
\text { turnover }\end{array}$ \\
\hline Micro & 5 & R0.20m \\
Small & 50 & R19m \\
Medium & 200 & R64
\end{tabular}

SMMEs have a key role to play in any industry, as they have the ability to contribute to job creation and growing the economy of the country. However, due to limitations on resources, skill and know-how, they are limited to certain areas of the value chain. The renewable energy value chain comprises manufacturing, professional services, transportation and logistics, construction, operation and maintenance and auxiliary services (see Figure 3).

- Manufacturing - equipment and component manufacturing and retail and resell solar PV systems.

- Professional services - depending on the size (capacity) of the system being installed, various services may be required, including design, project management, inspections etc. These services could be offered by small consulting companies.

- Transport and logistics - project development requires transportation of equipment and other materials to site.

- Construction - includes provision of civil, electrical and other engineering services.

- Operation and maintenance (O\&M) - depend- 
ing on the type of contract, O\&M services might be provided by the developer or outsourced.

- Auxiliary services - these services include ad hoc and non-technical services such as grass cutting, cleaning of panels, catering, etc.

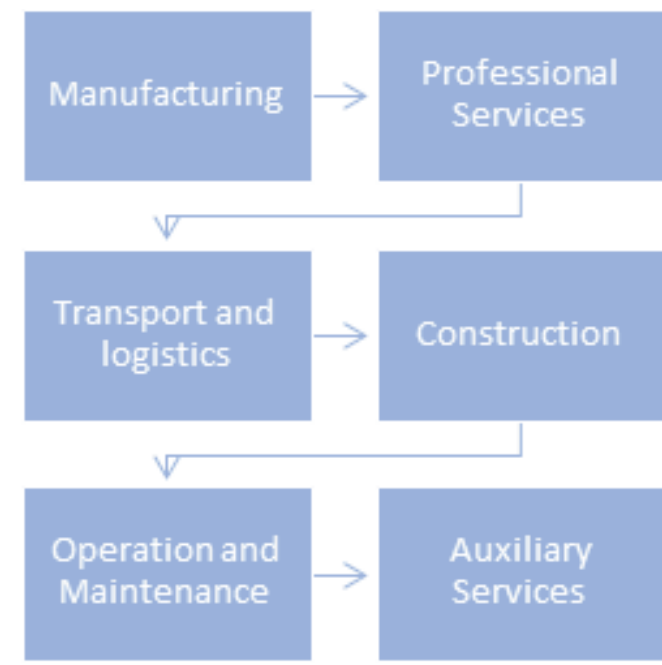

Figure 3: Renewable energy technologies value chain.

\section{Approach of the study}

Renewable energy has a number of technologies, but for this study, the main focus was on the evaluation of the technology that is the fastest growing in the SSEG environment, in order to be able to get a better understanding of the status and the opportunities that lie in this sector. A review of the SSEG developments in different provinces was made, by determining the trends in terms of the developments by the various role players, predominantly the investors or developers in the different sectors.

Qualitative research was carried out, where the outcome is based on the words and feelings from various sources and parties, instead of numbers, as explained by Snapsurveys (2018): "Qualitative Research is primarily exploratory research. It is used to gain an understanding of underlying reasons, opinions, and motivations. It provides insights into the problem or helps to develop ideas or hypotheses for potential quantitative research. Qualitative Research is also used to uncover trends in thought and opinions, and dive deeper into the problem". This method is useful in exploring the current state of the sector, to get insights into understanding the issues in this field, with regard to the participation of SMMEs.

Interviews were conducte with various industry role players, which provided insight on the current state of the SMME. This is another tool used in qualitative research, to collect data from a focus group identified (Gill, Stewart et al., 2008). The purpose of the interviews was to identify barriers and opportunities for SMMEs in the SSEG sector for consideration as an avenue for participating in the renewable energy industry. A questionnaire was developed and communicated with the relevant stakeholders; on their agreeing to participate, telephonic interviews and interviews in person were conducted. This approach allowed the respondents an opportunity to express their views about the industry, the growth, ease of participation, barriers encountered, etc. based on their encounters.

The information sourced was reported as a summary of the industry view, without isolating any individuals or parties to protect the participants. As per the suggestion by Gill, Stewart et al. (2008), the respondents were asked to participate formally in the research work, and were further informed about the information being treated confidentially and the assurance of anonymity, where the results were to be presented as a consolidated view of the industry. The details about the interview were shared with the participants prior the interview. The interviews were done with stakeholders such as the municipalities, enterprises predominantly that are medium sized which can be referred as investors, government departments (that were available). These stakeholders were chosen as they have a wealth of knowledge about the industry, through their experience.

\section{Findings}

\subsection{Industry status}

Engagements with the industry indicated that the municipalities play a critical role in enabling SSEG to grow, with no direct intervention from national government; except for support and approval of regulation by NERSA. With clear evaluation of the notion, the SSEG is seen to present new opportunities for the growth of the economy, job creation, the improved efficiency of the electricity provision due to the uptake of the large scale infrastructure in which the embedded generation are integrated hereto. Other opportunities include grid stability, sourced investments, customer satisfaction, and reduction of greenhouse emissions, within the municipalities.

The municipalities see SSEG as a local matter and they play a critical role in creating the required infrastructure and facilitating the necessary regulatory environment to enable the establishment and growth of the SSEG field. Guidelines are drafted by municipalities such as City of Cape Town, Nelson Mandela Bay Municipality and others.

The industry indicated that the installations of SSEG in the municipalities is primarily based on the solar PV installations, these dominating the industry. This is due to the prices of the PV components, such as silicon PV cells, having significantly dropped over the years (see Figure 4) and the ease of implementation -as opposed to other technologies, such as wind, which are viewed as capitalintensive. 


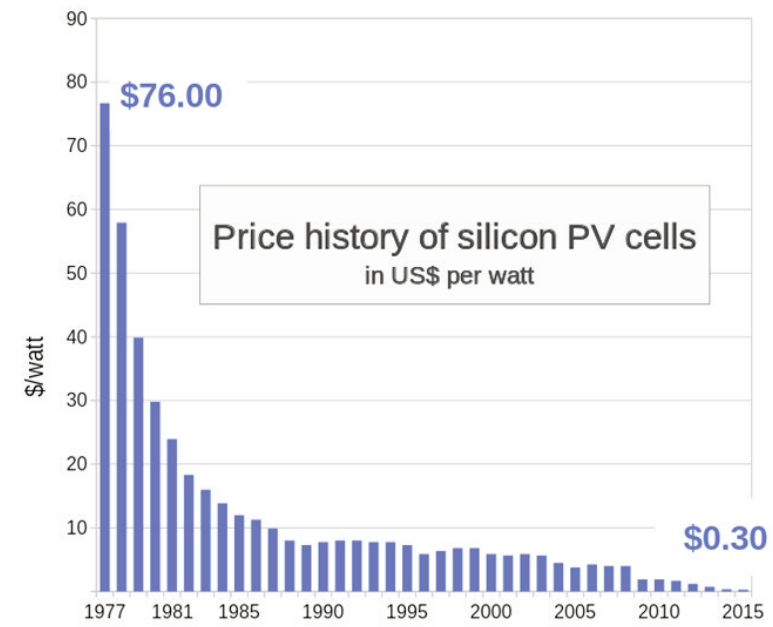

Figure 4: Prices of silicon PV cells

Source: Bloomberg New Energy Finance.

The increase of SSEG installations results from a number of factors such as the decrease in prices for panels, improved manufacturing technologies, improved efficiencies etc (Breyer and Gerlach, 2013b). Industry testified to this notion, and further indicated that in recent years SSEG was being considered due to its affordability, in comparison to earlier years. Findings also show that other technologies, such as wind, are used, but in smaller numbers. These are found in remote areas, for telecommunications sites and other applications with low power requirements, with capacity that range between 50KW and 1MW (Rycroft 2016); this was also confirmed by the industry role players interviewed, where they indicated that there are only a few small wind systems installed. Furthermore, developments show that interest from commercial and industrial consumers is growing, which has led to the development of turbines that are medium sized (with 2.5MW capacity) and at times are used as a combination with solar PV (Rycroft 2016).

\subsection{Participation of stakeholders in the SSEG sector}

The interviews conducted with the industry gave insights to the current state of the SSEG in South Africa and the level of participation of SMMEs in the industry. They confirmed that SMMEs install solar PV for both residential and commercial customers, where some are subcontracted by the investors (the latter term referring to the individuals or companies that have the capital to invest in purchasing and installing the solar systems).

Based on the engagements with some of the investors, where their role in the industry was reviewed, key activities, areas of operation and number of installations done, gave a good insight as to the trends of the industry. This was done in order to determine if the industry was on a growth or decline trajectory, based on the activities in the industry and the number of projects installed per year. Most of the investors interviewed started their businesses offering the installations of the solar systems to residential, commercial and industrial customers mostly in 2011 and 2012, with some in 2013. The number of installations done in the beginning was minimal, with some installing two systems in a year. However, these numbers improved as the industry matured, with some recording as many as 18 solar implementations in a year (2018, number to date). The investors further indicated that, on implementing such projects, small and micro enterprises were sub-contracted (where the investors are predominantly classified as medium or large enterprises) to provide services for installation and maintenance. This shows the growth in the industry and how it presents opportunities for the SMME sector.

The location of the projects was also tracked, for an indication of the provinces that were active and embracing the concept of SSEG. As per the investors interviewed, the leading provinces were Gauteng and Western Cape. Provinces such as the Eastern Cape have potential to increase the number of SSEG projects, where the municipality confirmed their approach and strategy in incorporating the renewable energy into their energy supply, following pressures that include a decrease in turnover as a result of the unaffordability of electricity for many customer (due to price increases) and the isolated solar system installations. The strategy therefore enables investors to install the systems for customers connected to the municipal grid at no cost to the customer, with reduced rates as a result of the system installation on their property. This in turn allows the municipality to facilitate the generated electricity by the investor's system. This can be viewed as a strategy that will stimulate the industry (both residential and commercial) due to its affordability (where no upfront payments are required).

Some of the case studies are observed where the National Department of Tourism implemented solar systems, coupled with batteries for storage on Robben Island for example, to promote sustainable tourism. Here the microgrid consisted of a 666.4 kW solar farm (Pallet 2017). According to Sola Future Energy, the system will generate close to a million $\mathrm{kW}$ annually. Such an implementation was done by an enterprise classified as medium-sized and consisting of a skilled labour force.

Other cases refer to the commercial buildings such as the shopping centres or malls that incorporate the systems. There have been a number of such establishments that incorporated the SSEG into their facilities, nationwide, including The Zone Mall, Vincent Park Mall, Secunda Mall, Centurion Mall, Stoneridge Mall, Clearwater Mall and Vaal Mall. Many more shopping centres are incorporating rooftop PV. Some of the observed market for the SSEG is the corporates. 


\subsection{Industry conduciveness for SMMEs}

The input shared by an official from a government department indicated that there are a few projects established by government agencies or parastatals such as SANEDI and Prasa, in various areas. When asked if the industry was conducive to SMME participation, the department agreed with industry that the environment was not enabling and encouraging SMMEs to participate in SSEG, as the regulation pertaining to SSEG was still not signed, and there were no direct incentives specifically for SMMEs operating in SSEG. According to the government official, more still needed to be done to rectify the current situation. The official confirmed that local content is encouraged by the government, but not enforced; it is considered within the department itself, if the department is in a process of procuring such a system. However, the department is not in a position to enforce private installations to be compliant, and can only encourage all businesses to consider using SMMEs when procuring services.

Energy storage has seen positive developments, as the costs of ion lithium batteries are also decreasing, as a result of investments from the electric vehicle industry. For example, the cost dropped by some $24 \%$ in 2017 alone. Other technologies in the pipeline include liquid metal batteries (said to be use relatively cheap components and manufacturing processes) and compressed air storage. These too offer opportunities for SMMEs as the industry grows.

4.4 Value chain and opportunities for SMMEs There are many activities that takes place in the implementation of a solar PV system. These activities, depending on the size of the project, are performed by various parties (on a subcontract basis), including SMMEs. Figure 5 shows a typical value chain for a renewable energy project, specifically referring to a solar PV system.

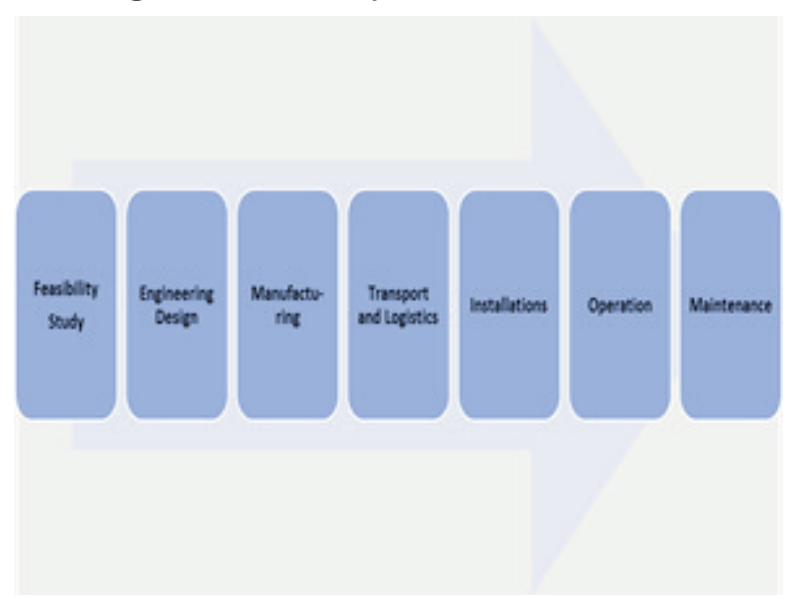

Figure 5: SSEG: Solar PV value chain.

Based on feedback from interviews, the industry is of the opinion that SMMEs have a higher poten- tial for participating and providing services in the value chain, as highlighted in Figure 6.

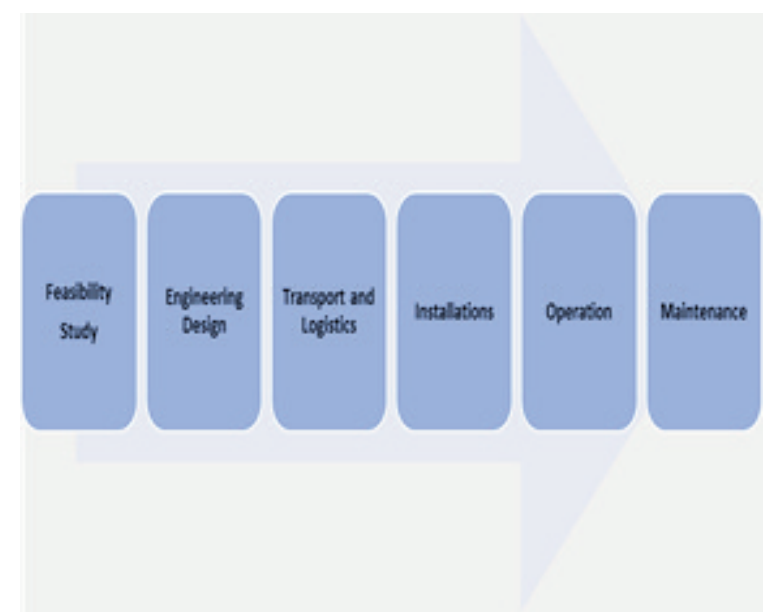

Figure 6: SSEG: SMME participation in the value chain.

Limited opportunities exist for manufacturing the solar system components, as it is a capital-intensive process and requires technical ability. Manufacturing is done abroad and the component imported, with China and Germany dominating the industry. In most cases, companies source the components and assemble them locally. The industry has indicated that SMMEs could participate in the SSEG value chain predominantly in installing, operating and maintaining systems. However, some with requisite skills also provide services that include feasibility studies and engineering design.

Industry role players have indicated that the industry is fairly capital-intensive, which excludes small and micro enterprises; it is medium and large companies that are capable of providing services and have the resources. Advice from one of the municipalities was that "for the small enterprises to participate in this industry, they need to consider being sub-contracted by the investor or contractor to provide specific services in the project". This is in light of the expensive resources required and the industry requirements, such as guarantees and warrantees.

Opportunities, or low-hanging fruits, available for SMMEs include:

- Installation: industry indicated that one service that can be seen as easy to access and participate in is installation of the panels, either as the main contractor or under a sub-contract from a more established entity.

- Maintenance: this is another avenue where SMMEs have an opportunity to play a role in, given fewer challenges that could hinder their participation. This as a service provided to the main contractor or investor, or directly to the customer

Other platforms identified as encouraging SMME participation in the solar PV industry include 
the introduction of the PV GreenCard, which the South African Photovoltaic Industry Association (SAPVIA) developed to promote high quality and safe installations. The main focus of the programme was on skills development, education and training to build installer capacity and to improve the standards for compliance (SAPVIA 2018). The GreenCard is seen as the quality label ensuring high standards in small-scale installations. According to SAPVIA, estimates show that in recent years just over 60000 installations have been made in residential, commercial and industrial market segments. During the interviews, the industry indicated that some customers lost confidence in the PV systems because of the poor quality some of the installers gave. Therefore, initiatives like the GreenCard programme can be viewed as a stimulant to the industry, due to the boost in the customer confidence that comes with quality and safe workmanship.

\subsection{Challenges for SMMEs in SSEG}

The SSEG industry is in a growing phase, but there are challenges experienced by the industry, particularly the SMMEs, as outlined in the interviews with industry and mapped in Figure 7.

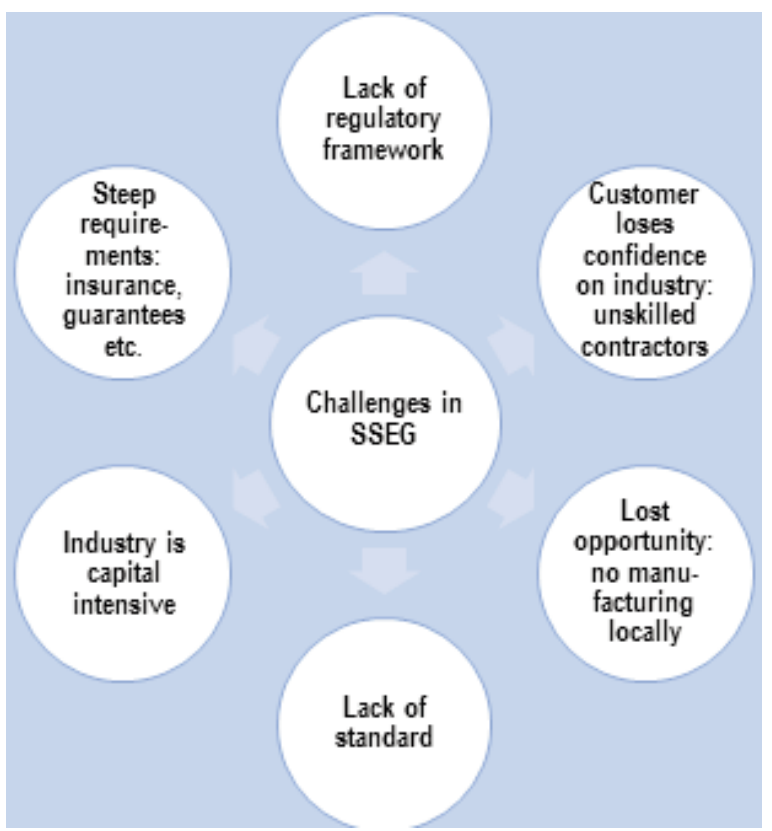

Figure 7: Challenges for SMMEs in SSEG.

The lack of regulatory framework limits growth and certainty for the industry players, in relation to issuing of permits or approval for connecting to the municipal grid, and more so for larger systems (bigger than the acceptable $100 \mathrm{~kW}$ capacity). The other challenge identified by the industry is the loss of confidence in SSEG due to poor quality supplied by other unqualified service providers that. Of key importance, the industry emphasized the challenge of SMME participation in the industry due to its capital-intensive nature. For role players to participate, high investments are required, for equipment, labour, and meeting the expected requirements. Closely related to that, a challenge pertains to providing customers with guarantees and warranties on work done, which comes at a cost to the investor/Installer. The industry indicated that the SMMEs are unable to provide the. The opportunity lost due to sourcing the main technology components from abroad, where the environment does not allow for local manufacturing, is seen as a disadvantage. There is no business opportunity in this value chain and no jobs created. Some industry players are of the opinion that the lack of standards giving specific requirements is detrimental to progress.

\section{Discussion}

Renewable energy incorporation into the energy mix has sparked interest from many participants in the industry, which has resulted in the electricity demand from the municipalities dropping, and this in turn decreasing revenue generation. It is for this reason that municipalities such as the Nelson Mandela Bay Municipality have taken a view of embracing the realities of change and incorporating SSEG into their strategy. Such incorporation by municipalities provides investors with an opportunity to implement SSEG there for interested customers. This in turn provides the small and micro enterprises with increased chances of participation in this sector.

Solar PV technology has been deemed by many in the industry as the fastest-growing, due to the decrease in its costs and new affordability. This presents opportunities for SMMEs to provide services in this sector. However, due to the nature of renewable energy technologies, which are capital-intensive, the industry suggests SMMEs should focus on installation and maintenance, and look for opportunities to be sub-contracted by the big contractors in the industry.

To enable the SMME to thrive in this industry, the government and the energy regulator should ensure that there are approved frameworks that the industry can base their work on, and will guide and allow the participation of SMMEs. In addition, incentives for SMMEs in SSEG would give them an added advantage and encourage their participation.

SSEG is on the increase, as evidenced by the number of implementations of solar PV systems. Factors such as the decrease in key components prices have stimulated the industry. Furthermore, the introduction of the PV GreenCard provides SMMEs an opportunity to gain confidence from the customers by being compliant with its requirements. 
In this instance, the SMME stands a better chance of appointment on SSEG implementations, as a service provider directly or as a sub-contractor to a project.

New developments in the industry, such as improved electricity storage technologies, present opportunities for SMMEs, by minimising criticism of the technology and perhaps, in the future, allow partaking in the value chain of this storage.

\section{Conclusions}

The renewable energy industry is growing in South Africa due to the Renewable Energy Independent Power Producer Programme. Small scale embedded generation (SSEG) is making a modest contribution to the industry, evident particularly with solar PV technology - which is seen as the fastest growing renewable energy technology. This offers small, medium and micro scale enterprises (SMMEs) an avenue to provide services. Based on the statistics from the industry participation with regard to installations of SSEG in sectors including residential, commercial and industrial, it can be concluded that the industry is growing. Geographically, the participation cuts across the provinces, with the sampled participants doing most installations predominantly in the Gauteng and Western Cape regions.

In the value chain of solar PV technology in SSEG, SMME participation is low, due to the capital-intensive nature of the industry. However, participation takes place in the provision of various services including construction, maintenance, design etc. Components are imported and assembled in the country.

According to the industry, some of the lowhanging fruits identified for SMME participation in the SSEG sector, particularly the small and micro enterprises, are in installation and maintenance. It was suggested that for SMMEs to increase their participation in the industry, they need to consider being sub-contracted by the investors or project developers.

The challenges identified by the industry for SMME participation in SSEG related to regulation, the market, steep requirements, high cost of capital, and the lack of local component manufacture. The government could alleviate such challenges by providing clear regulations and a framework for the industry. It is recommended that regulations around SSEG be finalised to give direction and standards for the participants, in order to grow the customer base. Incentives for SMME in SSEG should be considered by the government (Department of Trade and Industry and Department of Energy) to help alleviate the financial challenge for SMMEs and encourage and enable their participation. Furthermore, the small and micro enterprises stands a chance of growth when municipalities incorporate SSEG in their energy plans.

\section{Author roles}

E. Mkhwebane: data collection, desktop research and conducting interviews with the industry role players, data analysis and write-up.

N. Ntuli: research formulation, research methodology, desktop research and write-up.

\section{References}

Atkins, W., 2016. U.S. Department of Energy.

Baker, L. and Phillips, J., Tensions in the transition: The politics of electricity distribution in South Africa. SAGE Publications.

Banking Association of South Africa, 2018. Small business definition. Available: http://www.banking.org.za/what-wedo/sme/sme-definition [20 September, 2018].

Breyer, C. and Gerlach, A., 2013a. Global overview on grid】parity. Progress in Photovoltaics: Research and Applications, 21(1): 121-136.

City of Cape Town, 2017. Guidelines for embedded generation. Sustainable Energy Africa, British High Commission Pretoria.

GIZ, 2015. Net metering concept for small scale embedded generation in South Africa. White Paper.

Rogerson, C., 2008. Tracking SMME development in South Africa: Issues of finance, training and the regulatory environment. Urban Forum, 19(1): 61-81.

Rycroft, M., March 14, 2016-last update, Small wind turbines for private power generation. Available: http://www.ee.co.za/article/small-wind-turbines-private-power-generation.html.

Salga, G. and Genesis, 2017. Financial impact analysis of SSEG. GIZ.

SAPVIA, 2018. Promoting safe and quality solar PV installations. Available: https://www.pvgreencard.co.za/ [October 12, 2018].

Stellenbosch Municipality. Guidelines for small scale embedded generation in Stellenbosch Municipality.

Üçtuğ, F.G. and Azapagic, A., 2018. Environmental impacts of small-scale hybrid energy systems: Coupling solar photovoltaics and lithium-ion batteries. Science of the Total Environment, 643: 1579-1589.

Zhang, C., Wu, J., Zhou, Y., Cheng, M. and Long, C., 2018. Peer-to-peer energy trading in a microgrid. Applied Energy 220: 1-12 